\title{
Adolescent counselling services in the voluntary sector
}

\author{
Mary Mitchell
}

\begin{abstract}
Aims and method While Youth Access attempts to organise voluntary counselling services for young people on a national level, research describing such agencies is lacking. In order to investigate their activity with a view to multi-agency collaboration, a questionnaire was distributed to eight agencies in Hampshire.

Results The responses demonstrate a strong emphasis on accessibility and informality. Although agencies have reported increasing numbers of service user contacts little attempt has been made to quantify and evaluate the service provided.

Clinical implications Efforts to organise, evaluate and improve accountability in the voluntary sector might spoil these fundamental components for the disaffected adolescent.
\end{abstract}

In 1992 Youth Access emerged from the former National Association of Young People's Counselling and Advisory Service. Youth Access claims to be the only national network for voluntary adolescent counselling services (Youth Access, 1996). It claims to be organising the disparate voluntary adolescent counselling services by providing a central source of reference, information and advice on the proper development of such work. It provides a director of services nationwide. It produces publications on topics such as: good practice, confidentiality, developing services and insurance for counsellors. It aims to evaluate the usage of adolescent counselling services, to demonstrate the needs of young people and the relevance of the service to them. Youth Access hopes that all voluntary adolescent services will become members and follow their guidelines, providing some uniformity of service, of statistical analyses and of protection for volunteers as well as service users. At the moment such organisation is in its infancy. and as yet these services differ in many ways throughout the country. It is impossible to examine the work carried out on a national level. The number of adolescents attending such services is rising. In Portsmouth, the 'Off The Record' service, which has been in operation for 17 years, has seen a steady increase to as many as 6000 service user contacts each year.

The relationship between the voluntary sector and adolescent mental health services has been highlighted with suggestions for better collaboration (further details available from the author upon request) in the context of the Health Advisory Service document Together We Stand (Williams, 1995). In order to integrate the work effectively, the statutory services must acknowledge and understand the work carried out by the voluntary service. To date, little research has been published on this subject in the psychiatric literature except for a useful reference: Counselling For Young People by Mabey \& Sorensen (1995), a solitary effort to describe voluntary counselling services. It highlighted Hampshire as one of two regions at the forefront of the provision of voluntary adolescent counselling services. It seemed timely therefore to investigate the work being carried out in this area.

\section{The study}

The eight services for adolescents in Hampshire have organised themselves into the "Hampshire Network'. At one of the monthly Network meetings the aims of the study were explained and a questionnaire was distributed to the eight managers. In order to discover more about their work, questions were asked about the numbers of young people seen in the previous three years, the numbers and types of problems encountered, descriptions of the staff, premises and documentation. Of the eight questionnaires distributed. seven were returned and the replies provided a great deal of information on several relevant issues.

\section{Findings}

\section{Structure of the service}

Each agency had developed independently, its role determined more by funding sources than by need. One service received the bulk of its budget from the housing department and provided information and crisis accommodation to the homeless in the area. The other main sources of 
funding were youth services, county councils, health authorities, social services, education, charitable trusts and the National Lottery.

The services provide information (without assessment or recommendation) on issues such as contraception, drug and alcohol misuse, homelessness and social security benefits. Decisions on choice and action are left with the young person. The services also offer 'be-friending' in which a young person is introduced to others, who attend the service with similar problems. Some agencies organise group work, whereby a number of young people work together on issues such as bullying and self-assertion. A few agencies work in schools, taking part in personal development programmes on drug and alcohol misuse. Counselling is defined by Youth Access as an activity which is voluntarily entered into by a young person seeking help from someone trained and supervised in the counselling process. The aim is to create greater awareness of the young person's personal resources and their ability to cope with their life. 'Advice' is described as the process by which a young person is helped to change or cope with practical issues and problems by providing them with accurate information about their rights, options and potential courses of action.

\section{Problems encountered in counselling}

The majority of young people referred themselves to the services in Hampshire, but there were occasional referrals from general practioners, schools, probation and psychiatric services. None of the agencies was able to provide exact figures for the numbers of service users seen or particular problems encountered (approximate number of service user contacts, Portsmouth 6000 per annum; Isle of Wight, 2500; Aldershot, $5500-6000$. Further details available from the author upon request). Agencies were asked to list and rank the most frequently reported problems, and these were family breakdown, relationship difficulties and problems of low self-esteem. followed by housing difficulties, employment and benefits. It was not uncommon for issues related to abuse (physical, emotional or sexual) to arise in the counselling situation. There seemed to be a growing demand for help on drug misuse, problems related to teenage pregnancy and worries about sexually transmitted diseases.

\section{Experience and training of volunteers}

The counsellors were unpaid volunteers, all Caucasian, mostly female but with a wide age range (18-65 years). The volunteers had received at least 80 hours of training in counselling, and in most services promised a commitment of at least three hours each week. The volunteers came from all walks of life, some interested because they had seen their own children through to adulthood, others with degrees in psychology and allied subjects. Many had qualifications in youth work and mental health.

Every service provided regular training meetings to which local speakers (from the police, probation, health and education) were invited to share their specialist knowledge on relevant issues. The volunteers were expected to attend group supervision at least once each month, more frequently if the problem required it. In addition to the paid staff, who had varied backgrounds (youth work, social work, business), some services also provided support staff to accompany the volunteers and act as a receptionist or security guard, providing a degree of protection while the volunteer engaged in counselling.

\section{Security}

Facilities were usually cramped; one administrative area, one or two counselling rooms and a waiting area. The security systems in place varied greatly and there was no policy on personal safety. All services relied on the presence of two members of staff for mutual protection, some carried personal alarms, and one had a reliable caretaker. All services had encountered threatening situations, particularly from young people who were misusing drugs and also from those apparently suffering from a major psychiatric disturbance. Although infrequent, such incidents created anxiety among the volunteers, yet there was no uniform provision of panic buttons, or training in 'break away' techniques. With regard to documentation, each service had its own guidelines, some recording brief comments on each case and storing the information in locked filing cabinets on the premises, others keeping no details and some taking notes home. Most services keep basic statistics on the number of service user contacts not user numbers, and little attempt was made to evaluate the service provided.

\section{Comment}

The questionnaire was designed specifically to gather information in an uncritical manner. When basic statistics were requested, they were not always available, which made direct comparisons between services impossible. Measuring need and evaluating the effectiveness of the service was not a priority. There was no agreed policy on methods of evaluation, statistical collection and analysis, security, staff protection or documentation. Standardised questionnaires, helpful in the assessment of depression or anxiety were not used. 
The current service depends on the goodwill of unpaid volunteers and is relatively inexpensive to run. The voluntary agency can offer confidentiality more readily than any statutory service which may be bound to disclose information according to Child Health Legislation. However, all agencies do agree on a general policy to protect young people and do the upmost to minimise danger. More than the statutory services, voluntary agencies can offer various forms of assistance without the same need to justify or demonstrate cost-effectiveness. At the present time there is a reluctance to gather information from young people, which he or she may be reluctant to give. There is not a strong emphasis on counting the numbers and types of problems seen and measuring outcome. The volunteers are not demanding better working environments or worried about litigation. If the voluntary agencies were to address these organisational short-comings, the increasing bureaucracy might be detrimental to the friendly and informal accessibility of the current disparate service and spoil the most useful component for the troubled anti-establishment adolescent.

It would seem logical that all services attempting to meet the need of the growing number of adolescents with emotional problems should have some knowledge of the different types of provision. In times when resources are scarce it would make sense to use all that is avallable to young people. Despite the limited resources of the adolescent counselling services, young people are seeking out these agencies in increasing numbers. The work of unpaid volunteers should be acknowledged by health professionals who might sometimes benefit from joint working. Voluntary services might fill the gap left by inadequately funded statutory services, but without an organised system of evaluation the voluntary sector can only be described at the local level. Each professional would have to investigate the agency in his or her area. Good working relations may be possible but all involved would need to remain clear about their abilities and limitations and to concentrate their efforts on increasing appropriate resources. Any attempt to evaluate and organise such voluntary agencies might spoil that part which is essential to their success.

\section{References}

MABEY, J. G. \& SORENSEN, B. (1995) Counselling for Young People. Oxford: Oxford University Press.

WILLIAMS, R. (1995) Together We Stand: The Commissioning Role and Management of Child and Adolescent Services. London: HMSO.

YOUTH ACCESS (1996) Core Principles. London: Youth Access.

Mary Mitchell, Senior Registrar, Child and Adolescent Psychiatry Department, G level, Southampton General Hospital, Tremona Road, Southampton SO16 6YD

\title{
Readability of user leaflets
}

\author{
Harriet Humfress and Ulrike Schmidt
}

\begin{abstract}
Aims and method Leaflets are commonly used as a way of providing information to users. In this study, we use a simple index of 'readability' to compare a range of leaflets available to people with mental health problems.

Results The majority of the leaflets contained passages that are likely to be beyond the comprehension of people with mental health problems. Clinical implications Leaflets are a cost-effective way of providing information, but only if the text can be understood by the target audience.
\end{abstract}

Much emphasis has recently been put on increasing user involvement in psychiatric care. One aspect of this is to give users more information to help them understand their illness and to explain about different treatment options and services available to help them. An economic way of providing users with such information is by way of written material in the form of leaflets or factsheets.

Over about the past eight years, the Royal College of Psychiatrists has published 14 patient factsheets and 10 'Help is at Hand' leaflets on a variety of psychiatric disorders and their treatment. Many users may, however, prefer more independent information other than from a professional body and MIND has also published a similar series of leaflets. For patients detained under the Mental Health Act 1983, written 